\title{
The Innovative Technology of Hydraulic Compression and Boosting for Filling the Vehicles and Storage Systems with Natural Gas and Biomethane
}

\author{
Aleksey SAFRONOV ${ }^{1}$, Julia GUZEYEVA ${ }^{2 *}$, Jevgeniy BEGENS ${ }^{3}$, Ansis MEZULIS ${ }^{4}$ \\ ${ }^{1-3}$ Hygen Ltd, Matisa iela 103A-3, Riga, LV-1009, Latvia \\ ${ }^{4}$ Laboratory of Materials for Energy Harvesting and Storage, ISSP UL, Latvia
}

\begin{abstract}
The article describes the technology of the "hydraulic piston", as well as the studies that confirm the viability of this technology, implemented in various devices, designed to compress natural gas (CNG) and biomethane (bio-CNG), to accumulate CNG and bio-CNG, to deliver bio-CNG from the production site to the point of its injection into the natural gas network or to the vehicle fuelling stations to fill the Natural Gas Vehicles (NGV). The article presents prototypes of personal fuelling devices and mobile fuelling systems developed by Hygen Ltd. (Hygen), thereby showing the potential of the technology to contribute in the deployment of alternative fuel infrastructure and into the global GHG emissions reduction, mainly in the transport sector.
\end{abstract}

Keywords: Alternative fuel; compressed biomethane (bio-CNG); compressor; decarbonisation; gas storage; greenhouse gas (GHG); renewable gas

\begin{tabular}{|ll}
\hline Nomenclature & \\
bio-CNG & Compressed biomethane \\
bcm & Billion cubic metres \\
CNG & Cascade fuelling \\
EU & Compressed natural gas \\
EV & European Union \\
GHG & Electric vehicles \\
ICEV & Greenhouse gas \\
NGV & Internal combustion engine vehicles \\
PF & Natural gas vehicle \\
TRL & Parallel fuelling \\
VFA & Technology Readiness Level \\
\hline
\end{tabular}

* Corresponding author.

E-mail address: julia@hygengroup.com

(C)2020 Aleksey Safronov, Julia Guzeyeva, Jevgeniy Begens, Ansis Mezulis.

This is an open access article licensed under the Creative Commons Attribution License (http://creativecommons.org/

licenses/by/4.0), in the manner agreed with Sciendo. 


\section{INTRODUCTION}

Accelerating the decarbonisation process, biomethane (renewable gas) can be easily used to fuel the vehicles and to reduce their carbon footprint. Natural gas infrastructure and vehicles are fully compatible with renewable gas, without extra costs. Through renewable gas from municipal waste or Power-to-Gas production pathways, close-to-zero greenhouse gas emissions are achieved. In a recent study from Centre on Regulation in Europe (CERRE) a production potential of $124 \mathrm{bcm} /$ year renewable gas at EU level has been estimated [1].

Implementation of electric vehicles (EVs), especially in highly polluted city centres plays a great role in decarbonisation as well as in noise levels reduction in the urban areas [2]. However, the study of International Energy Agency (IEA) states that in the countries, where electricity production is based mostly on fossil fuels, Well-to-Wheel emissions for EVs are associated even with more GHG emissions than internal combustion engine vehicles ICEV [3].

Natural (also renewable) gas technology is ready to provide a fast and strong contribution to the challenge of decarbonisation. In 2018, several countries devoted considerable shares of renewable gas to transport, namely Iceland (100\%), Sweden $(90 \%)$, the Netherlands $(55 \%)$, Finland (50\%) and Switzerland (25\%), making carbon neutrality in transport already a reality [4].

The amount of Well-to-Wheel GHG emissions from various automotive fuels, recalculated to $\mathrm{CO}_{2}$ equivalent, is given in Fig. 1.

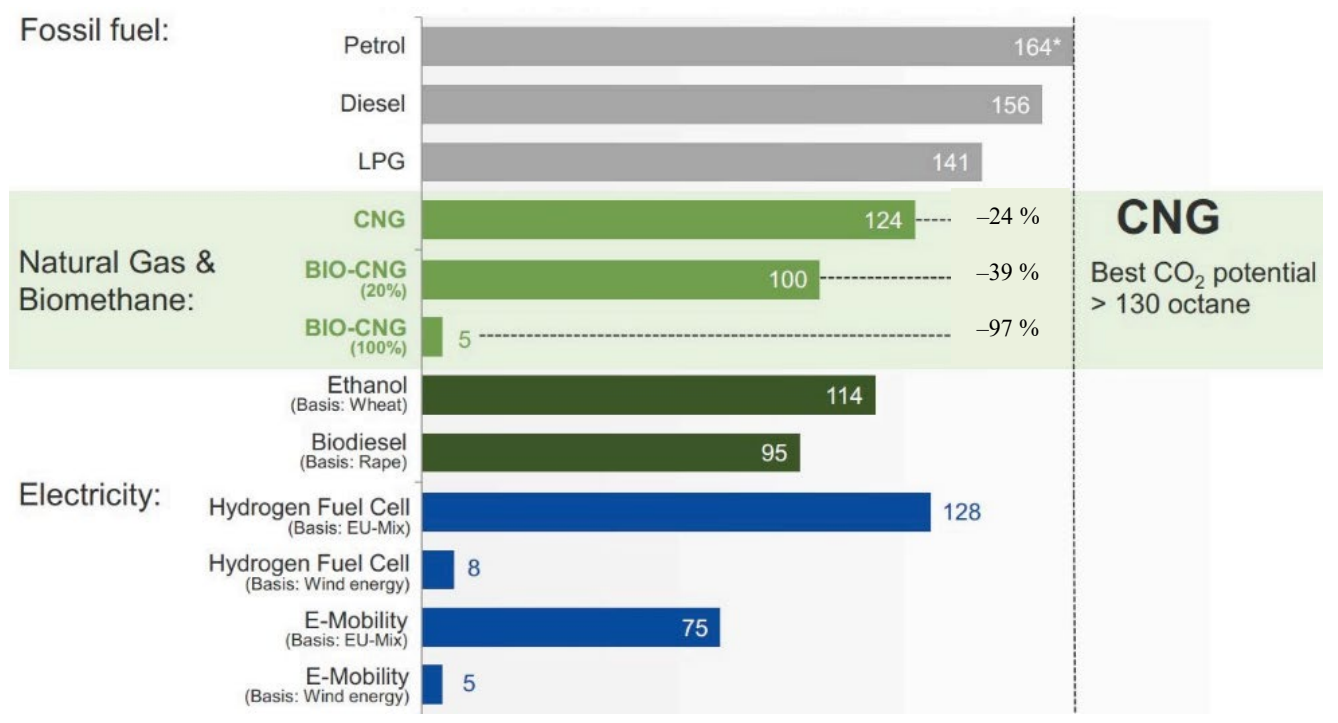

Fig. 1. Well-to-Wheel- GHG emissions in $\mathrm{CO}_{2} \mathrm{~g} / \mathrm{km} \mathrm{[5]}$.

The diagram shows that $\mathrm{CO}_{2}$ emissions are close to zero $(5 \mathrm{~g} / \mathrm{km})$ only in case, when electricity is produced from the wind (or from similar renewable sources). EU-mix electricity application for transport provides $\mathrm{CO}_{2}$ reduction comparing to the petrol only as $75 \mathrm{~g} / \mathrm{km}$, however bio-CNG shows the same low level of emissions, as E-mobility using wind energy for electricity production. Also, the diagram on Fig. 1 shows that the biogas when blended 
with the natural gas, plays a significant role in $\mathrm{CO}_{2}$ reduction: adding of $20 \%$ biogas to the natural gas gives $39 \%$ of $\mathrm{CO}_{2}$ reduction, comparing to petrol.

The Directive of the European Parliament and of the Council on the deployment of alternative fuel infrastructure (DAFI) defines the alternative fuels. One of them is the natural gas, including biomethane - the upgraded biogas. DAFI sets out minimum requirements for the building-up of alternative fuels infrastructure, including refuelling points to be implemented by means of Member States' national policy frameworks [6].

The European Biogas Association (EBA), the Natural \& bio Gas Vehicle Association (NGVA Europe) and the European Automobile Manufacturers' Association (ACEA) on January 21, 2020 called on EU policy makers to accelerate the deployment of infrastructure to deliver natural gas and renewable gas/biomethane across the European Union [7]. The revised Renewable Energy Directive (RED II), increases the overall EU renewable energy consumption target by 2030 from $27 \%$ to $32 \%$. RED II sets a minimum transport fuel share of $14 \%$, which must be produced from renewable energy sources to 2030 [8].

The renewable gas produced today is fully in line with the strictest sustainability criteria established through European legislation. By 2030, the gas mobility market has a growth potential 10 times higher than today, reaching a fleet of 13 million units. In parallel, the production of renewable gas will increase drastically: for 2030, a conservative estimation demonstrates a production potential of close to $45 \mathrm{bcm} /$ year, largely overcoming the entire demand for gas fuel of about $30 \mathrm{bcm} /$ year, which corresponds to a 13 -million-unit fleet. This would significantly contribute to the European decarbonisation path: $30 \%$ renewable gas will provide a GHG emissions reduction of more than $45 \%$ compared to conventional fuels on a Well-to-Wheel basis [4].

\subsection{Biomethane}

Biogas typically contains $55-75 \%$ methane and has an energy value of $5.0-7.5 \mathrm{kWh} / \mathrm{m}^{3}$ (energy value of a pure methane is $9.97 \mathrm{kWh} / \mathrm{m}^{3}$ ) [9]. In order to use biogas as biomethane fuel, it must be purified to an appropriate quality as defined by national directives. Numerous biomethane purification technologies from biogas are developed, allowing to achieve up to $99 \%$ purification. [10]

Biomethane production delivers $\mathrm{CO}_{2}$ neutral production. It particularly suits on-farm use by agricultural vehicles as farmers already possess the raw materials and the space to produce the biogas and upgrade it up to biomethane. This enables agri-business to be fuel sufficient. In addition, biomethane can be injected into the gas grid to power communities, creating a truly virtuous cycle.

\subsection{Currently Available Technologies of NGVs Fuelling}

Existing technologies allow biogas compression and dispensing by widely presented on the market mechanical CNG compressors, e.g., COLTRI [11] or FuelMaker [12]. They can be installed on biomethane production site and perform light duty and agricultural vehicle fuelling by time-fill, requiring 5-8 hours, depending on the productivity of compressor and volume of the vehicle's fuel tank. Existing vehicle fuelling solutions employ reciprocating compressor technology and due to that are less reliable. These compressors use an electric motor to rotate a crankshaft, which is tied to several metal pistons that pump to compress the gas. This technology requires pistons and piston rings, crankshaft and bearings, cylinders and valves. Since all these components generate friction and heat during operation, the compressor and related components require regular maintenance and a complete compressor 
overhaul at specified service intervals, which is costly. And, even with a regular servicing, unexpected component failure is often experienced [13]. In many cases, the combined maintenance costs end up being higher than the cost of the equipment itself. Since most of the components in reciprocating compressor solutions are specifically designed and manufactured, these tend to cost more and often have longer lead times for replacement parts. In addition, reciprocating compressors may cause unwanted vibration, and resonance in the pipelines [14].

To deliver biomethane from the production site to the customer or to the point of injection into the gas grid the mobile storage systems are applied. The existing on the market mobile storage systems allow to avoid the development of the costly new pipelines, however they require mother station on the biomethane production site and daughter compressing stations on the vehicle fuelling site, that adds the costs to such a project. Besides that, the existing mobile storage systems, based on free gas flow dischargement principle (both buffer and cascade), does not allow complete discharge of the storage system, - the "parasitic" volume of gas will always present in the storage cylinders [15].

\subsection{Main Challenges for Biomethane Application in Transport Fuelling Sector}

The technical problems of widening biomethane application to be resolved are:

- storage cylinders filling to high pressure in efficient way;

- bio-CNG delivery to the destination (injection point to the grid or fuelling station);

- development of an efficient fuelling appliance for on-farm application;

- complete gas storage cylinders dischargement.

The complete dischargement of the gas storage cylinders is a quite challenging task, because the fuelling from the gas storage systems, when being performed by a free flow of gas ends when the pressures are equalized between the gas storage cylinders and the target fuel tank. Simultaneous discharge of multiply storage cylinders is named "parallel fuelling" (PF). Another option is a serial discharge of multiply storage cylinders, named "cascade fuelling" (CF).

Comparing PF vs CF, the major benefit of CF is that this method refuels the target tank to higher pressure. Fig. 2 displays numerical simulation of filling of a $130 \mathrm{~L}$ target tank with initial natural gas pressure of 5 bars from the storage of four cylinders, $22 \mathrm{~L}$ each, being filled with compressed to 200 bar natural gas, by both PF and CF methods.

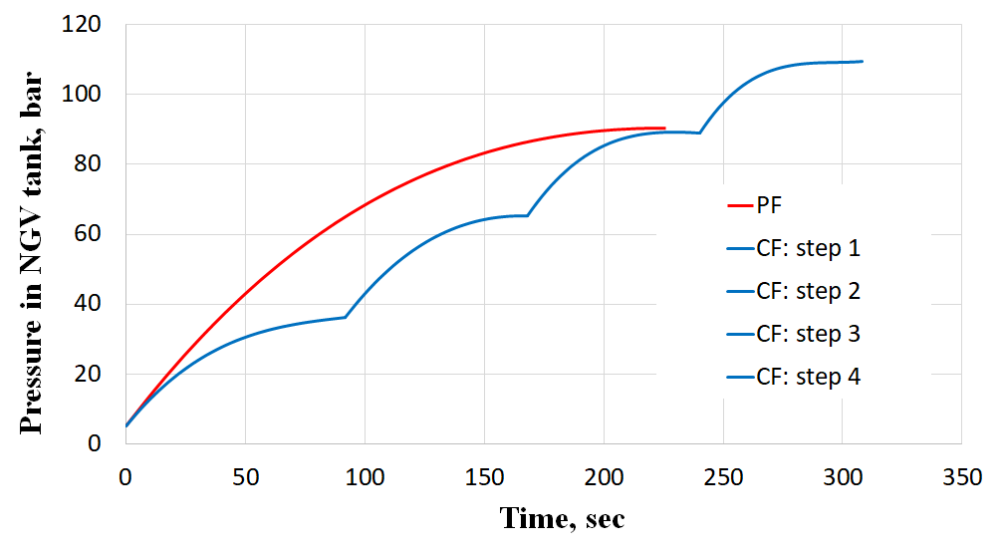

Fig. 2. Numerical simulation of complete cascade fuelling (CF) and parallel fuelling (PF). 
From Fig. 2 it is seen that CF reaches 109 bars in the target tank, comparing to 90 bars of the PF. The third cascade fuelling step out of four almost reaches the ending pressure of PF. Nevertheless, the possible achievement of the multiple cascades of reasonable number is far from required pressure, close to 200 bars, in a target tank. Besides that, the cascade principle has a significant disadvantage - multiple cylinders require complicated piping and valve triggering circuits. The only reasonable way to discharge the storage volume close to entirely is to employ a kind of boosting, i.e., to apply a pushing force.

\section{Methods And Methodology}

Latvian engineer Aleksey Safronov has invented and patented in 2008 a new method for hydraulic compression of gaseous fuels (Hydraulic piston) and a device for implementation thereof (the international application number: PCT/LV2008/000007, dated September 9, 2008) [16]. Hygen has developed the Technology of hydraulic piston and implemented it in various compressed natural gas vehicle fuelling systems intended for gas compression, accumulation and discharge (extortion). Unlike conventional and world-wide available mechanical multistage compressors, the technology of hydraulic piston uses a method of gas compression by means of a working fluid, which is pushed by a sufficiently powerful hydraulic pump. The technology of hydraulic compression allows to solve all problems mentioned in section Main Challenges for Biomethane Application in Transport Fuelling Sector, with minimal costs, since devices made on the basis of hydraulic piston technology use mass-produced components widely available on the market. By solving economic problems of gas compression and delivery the technology opens the door for wider application of bio-gas on transport. This contributes to solving the environmental problems associated with the effects of greenhouse gases from transportation that cause climate change, and the social problems associated with the impact of noise and harmful emissions on human health.

\subsection{Method of the Hydraulic Piston Compression}

Hydraulic gas compression has many significant advantages over a mechanical, where the latter is characterised by a high noise level, high temperature, rapid wear of moving parts.

The technology of hydraulic piston can be explained with a help of Fig. 3:

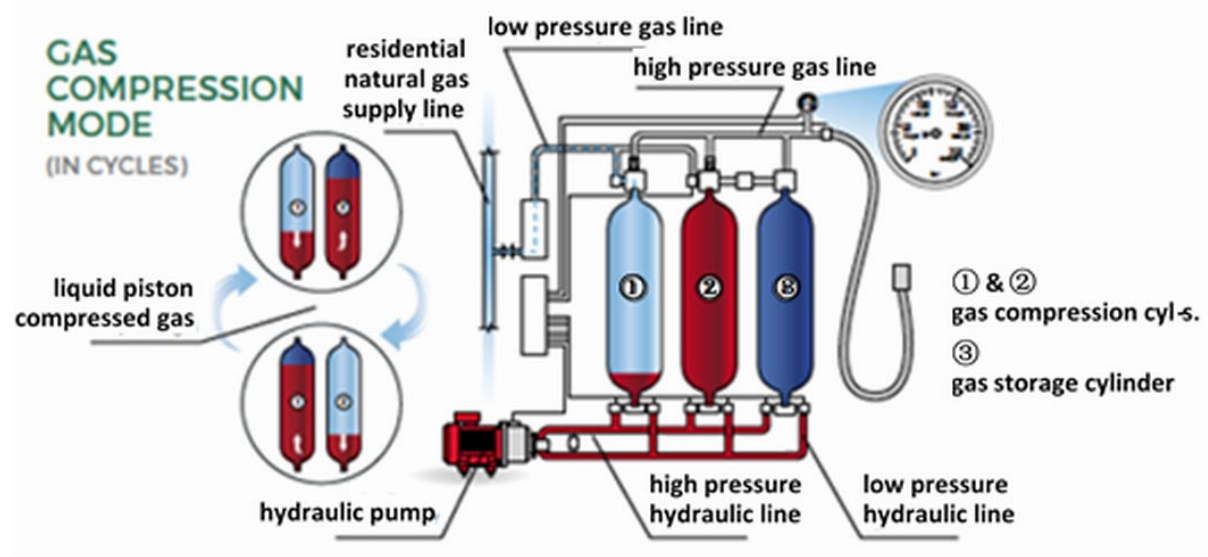

Fig. 2. Hydraulic piston compressor and storage. 
Cylinders 1 and 2 are paired to form a hydraulic compressor. The amount of the working liquid (red fill in Fig. 3) slightly exceeds the volume on one compressing cylinder. The working liquid is transmission oil that has been chosen to avoid any chemical reaction with the gas, as well as to have minimal gas diffusivity. One of the compressing cylinders is filled with low pressure gas, the other one - with hydraulic liquid. By rotating the hydraulic pump and triggering the valves, the working liquid is alternately pumped from one of the compressing cylinders to another and back. Supplying the liquid to the cylinder, which is filled with gas, results in gas compression and forcing out into the storage cylinder. At the same time, decrease of liquid level in another compressing cylinder allows a new portion of low-pressure gas to be supplied into this cylinder. Such alternative pumping of hydraulic liquid results in gradual pressure growth in the storage cylinder 3 up to 200 bars $\left(\right.$ at $\left.15^{\circ} \mathrm{C}\right)$, preparing the device for fuelling a vehicle. The main technological problem was to prevent the penetration of the working liquid from the compressing cylinder into the gas line. This problem was solved by invention of the multi-valve, which is placed in the neck of the compressing cylinder and provides a safe shut-off, when the working liquid reaches the top of the compressing cylinder. The multi-valve is a part of the Hygen patent [16].

\subsection{Method of Hydraulic Piston Boosting}

In order to empty the storage cylinder 3 of gas far behind the free flow principle, the boosting mode is implemented. The principle of boosting is displayed in Fig. 4.

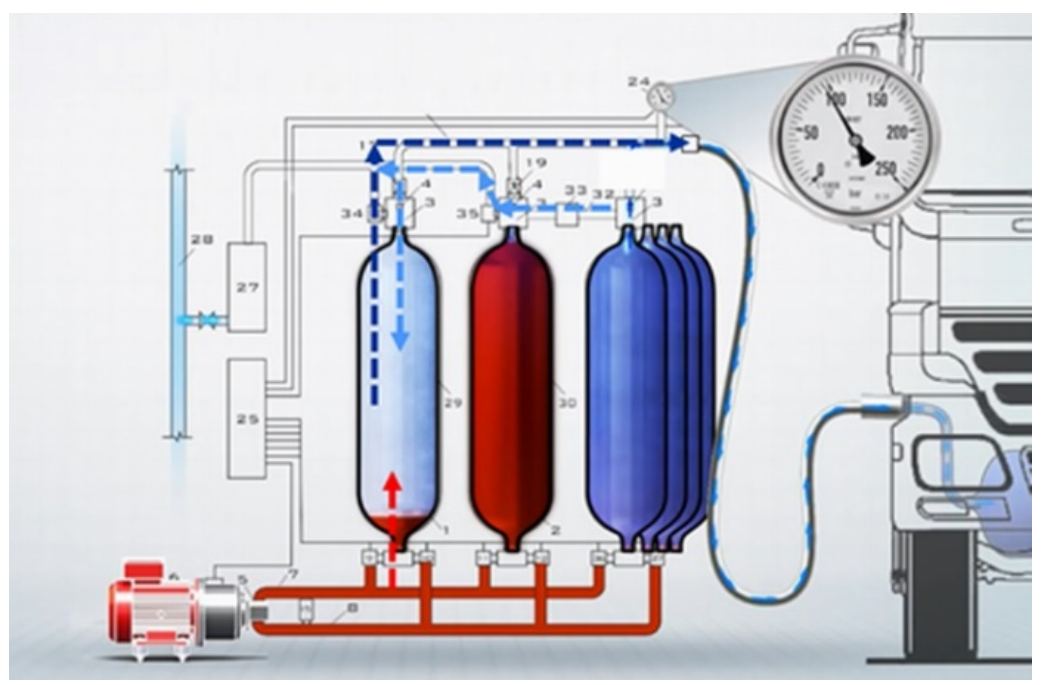

Fig. 3. Hydraulic piston operating in a boosting mode.

At connecting the storage tank to the vehicle's filling nozzle, the fuelling occurs by free flow until pressure equilibrium is achieved. After the free flow stage, the remained highpressure gas from the storage cylinder (light blue arrow) is supplied to the compressing cylinder for boosting, where it is further compressed (by acting the hydraulic piston) and forced out directly into the vehicle's fuel tank (dark blue arrow). Boosting cycles repeat alternately in the compression cylinders. The number of boosting cycles to achieve 200 bars pressure in the vehicles fuel tank depends on the volume and initial pressure of the tank. In case 
of a light duty vehicle with a standard fuel tank, 1-3 boosting cycles will be enough to fill the vehicle completely.

\section{Results}

The hydraulic piston technology was tested in the framework of Plan of Latvia Development 2020, in a research project KC1.2.1.1/18/A/008 lead by Mechanical Engineering Competence Centre and by Hygen proven team of high-level specialists from engineering, hydraulics, electronics and physics. The tests were performed on a Hygen testing bench.

The aim of the project was to test the behaviour of hydraulic piston at different inlet pressures and to study the technology at higher inlet pressures and flow rates, i.e., at boosting stage conditions. All tests have been performed with the aim to develop economically efficient smart vehicle fuelling appliance, capable to provide vehicle fuelling up to 200 bar pressure. Performed tests simulated different vehicle tank volumes, different inlet pressures and different emergency situations. The boosting mode was tested on the testing bench with two pairs of compressing cylinders and four storage cylinders. Electricity consumption, as well as gas quality after its contact with hydraulic piston were measured.

\subsection{Gas Inlet Pressure Tests}

The compression mode has been tested at various gas inlet pressures in a wide range. The hydraulic pump with productivity of $8.6 \mathrm{~L} / \mathrm{min}$, driven by $4 \mathrm{~kW}$ electric motor was applied. During each test a $100 \mathrm{~L}$ storage cylinder was filled with natural gas up to 200 bars. Gas flow rate has been calculated at three gas inlet pressure steps, Table 1.

Table 1. Hydraulic Pumping Rate at Three Gas Inlet Pressure Steps

\begin{tabular}{llll}
\hline No. & $\begin{array}{l}\text { Gas inlet } \\
\text { pressure, bar }\end{array}$ & Flow rate, $\mathbf{~ m}^{\mathbf{3}} / \mathbf{h}$ & $\begin{array}{l}\text { Pumping rate to inlet } \\
\text { pressure, } \mathbf{~ m}^{\mathbf{3}} / \mathbf{h} \cdot \mathbf{b a r}\end{array}$ \\
\hline $\mathbf{1}$ & 3 & 1.14 & 0.38 \\
$\mathbf{2}$ & 6 & 2.3 & 0.38 \\
$\mathbf{3}$ & 16 & 5.17 & 0.32 \\
\hline
\end{tabular}

Results of Table 1 testifies that flow rate, related to gas inlet pressure, starts slightly reduce after 6 bars, and the reduction is less than $20 \%$ up to 16 bars. Such characteristics is eligible for a proper compression of gas at inlet pressures in impressive $17 \mathrm{mbar}-16$ bar range.

\subsection{Boosting Stage Tests}

If the volume of the target tank is smaller than that storage capacity of the testing bench, fuelling up to 200 bars is rather simple and fast. For example, to fill a volume of $240 \mathrm{~L}$ the compressor operated in a boosting mode for about $13 \mathrm{~min}$, and the total electrical consumption of the device during this period is $1.12 \mathrm{kWh}$. The gas temperature in the tank first decreases until $-8{ }^{\circ} \mathrm{C}$ due to the gas expansion and then increases to $35{ }^{\circ} \mathrm{C}$ at the end of the filling (ambient temperature at $8^{\circ} \mathrm{C}$ ). Fig. 5. displays fuelling the target tank of $240 \mathrm{~L}$ at 85 bars from the storage capacity of $400 \mathrm{~L}$ at 200 bars. 


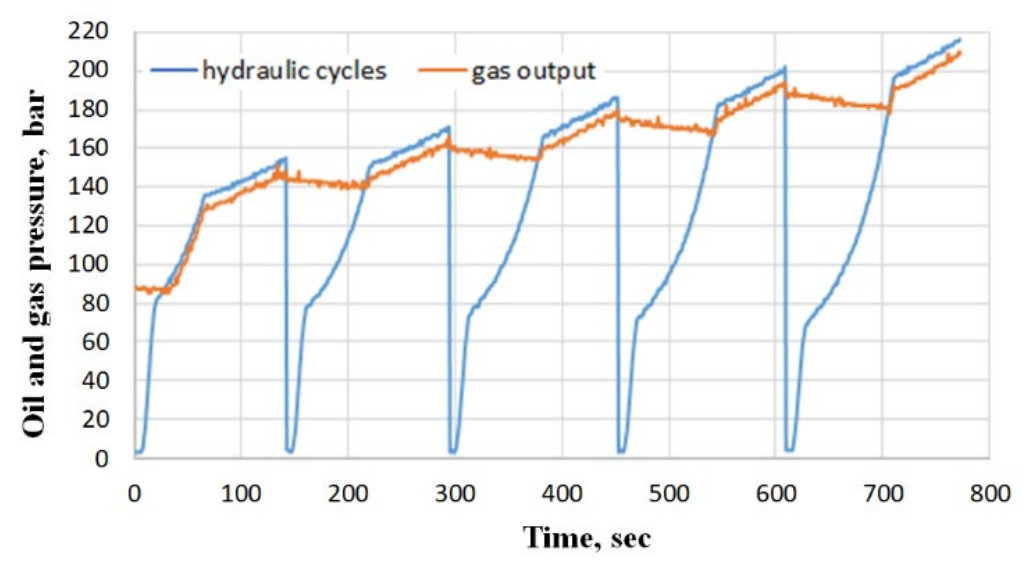

Fig. 4. Boosting stage of fuelling a target tank.

As the volume of the target tank is smaller, $400 \mathrm{~L}$ storage capacity is enough to fill the target tank up to nominal 200 bars. It takes 5 hydraulic boosting cycles and about $760 \mathrm{~s}$ of time, Fig. 5.

\subsection{Temperature Tests Results}

The tests proved that during both compression and boosting cycles the downstream temperature of the gas does not reach the safety threshold of any type of a standard fuel tank.

Two different cooling systems were tested: liquid and air. Both of them showed good results. Temperature of the gas supplied to the target tank after compression and after boosting modes did not exceed $60^{\circ} \mathrm{C}$. The air-cooling system was chosen for application in the prototype due to its simplicity comparing to the liquid cooling system.

\subsection{Gas Analysis}

With the liquid piston compression and boosting the gas fuel is in molecular contact with the working liquid, periodically up to 200 bars pressure. It is necessary to ascertain, are not the liquid molecules captured by gas, thereby making the gas fuel polluted.

Gas analysis was performed as follows: the natural gas sample has been taken at the outlet of the Hygen testing bench on a $1 \mathrm{~L} 40$ bars pressure cylinder. Additionally, natural gas at the outlet of the network has been sampled in order to evaluate the composition modification after a contact with working fluid under 200 bar pressure. The analysis has been performed using Thermal-Desorber/Gas-Chromatography/Mass Spectrometry (TD/GC/MS) and micro-Gas Chromatography $(\mu G C / M S)$. The results of these gas analysis are presented in Table 2.

If the general differences regarding the Aliphatic hydrocarbons are not significant between the two samples, one can notice that the heavy aliphatic hydrocarbons C14-C16 is rather high $\left(0.9 \mathrm{mg} / \mathrm{cm}^{3}\right)$. This might originate from the working liquid of the compressor that could volatize into the gas fuel. 
TABLE 2. Results OF GAS ANALYSIS

\begin{tabular}{|c|c|c|c|}
\hline Permanent gases & C Number & Reference & HYGEN \\
\hline $\mathrm{CH}_{4} \%$ & - & 92.64 & 89.92 \\
\hline $\mathrm{CO}_{2} \%$ & - & 0.8 & 1.79 \\
\hline $\mathrm{N}_{2} \%$ & - & 1.43 & 1.22 \\
\hline 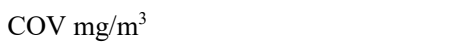 & C Number & Reference & HYGEN \\
\hline Total Aliphatic Hydrocarbons $\mathrm{mg} / \mathrm{m}^{3}$ & - & 79539 & 111200 \\
\hline Ethane & $\mathrm{C} 2$ & 53831 & 69170 \\
\hline Propane & $\mathrm{C} 3$ & 11498 & 24023 \\
\hline Isobutane & $\mathrm{C} 4$ & 6825 & 7520 \\
\hline Butane & $\mathrm{C} 4$ & 3132 & 6112 \\
\hline Aliphatic hydrocarbons $>\mathrm{C} 6-\mathrm{C} 8$ & $\mathrm{C} 6-\mathrm{C} 7$ & 2158 & 1626 \\
\hline Aliphatic hydrocarbons $>\mathrm{C} 5-\mathrm{C} 6$ & $\mathrm{C} 5$ & 2005 & 2717 \\
\hline Aliphatic hydrocarbons $>\mathrm{C} 8-\mathrm{C} 10$ & $\mathrm{C} 8-\mathrm{C} 9$ & 85 & 24.5 \\
\hline Acetylene & $\mathrm{C} 2$ & 3.8 & 4.4 \\
\hline Aliphatic hydrocarbons $>\mathrm{C} 10-\mathrm{C} 12$ & $\mathrm{C} 10-\mathrm{C} 11$ & 0.82 & 1.26 \\
\hline Aliphatic hydrocarbons $>\mathrm{C} 12-\mathrm{C} 14$ & $\mathrm{C} 12-\mathrm{C} 13$ & 0.07 & 0.09 \\
\hline Aliphatic hydrocarbons $>\mathrm{C} 14-\mathrm{C} 16$ & $\mathrm{C} 14-\mathrm{C} 15$ & $<0.06$ & 0.9 \\
\hline Alcohol mg/m $\mathrm{m}^{3}$ & C Number & Reference & HYGEN \\
\hline 1-Butanol (n-Butanol) $\mathrm{mg} / \mathrm{m}^{3}$ & - & $<0.06$ & 2.9 \\
\hline Ester $\mathrm{mg} / \mathrm{m}^{3}$ & C Number & Reference & HYGEN \\
\hline 2-Propenoic acid, 2-methyl-, butyl ester & - & $<0.06$ & 0.07 \\
\hline Mercaptan /Sulfure $\mathrm{mg} / \mathrm{m}^{3}$ & C Number & Reference & HYGEN \\
\hline Hydrogen disulphide $\left(\mathrm{H}_{2} \mathrm{~S}\right)$ & - & $<1.5$ & $<1.5$ \\
\hline Silane/ Siloxane $\mathrm{mg} / \mathrm{m}^{3}$ & C Number & Reference & HYGEN \\
\hline Cyclotetrasiloxane, octamethyl- (D4) & - & $<0.06$ & 0.09 \\
\hline Total COV (without $\mathrm{H}_{2} \mathrm{~S}$ ) $\mathrm{mg} / \mathrm{m}^{3}$ & & 79605 & 111250 \\
\hline
\end{tabular}

The presence of siloxane was observed at the outlet of Hygen testing bench with a nonsignificant value closed to the detection limit. One of the reasons of this observation could be a pollution of the Gas Chromatography column. Measured $0.09 \mathrm{mg} / \mathrm{m}^{3}$ is however compliant with the limit of EN 16723-2 [17], which set the limit of silica compound at $0.3 \mathrm{mg} \mathrm{Si} / \mathrm{m}^{3}$.

The overall gas composition at the outlet of Hygen testing bench is satisfactory for the use in a gas engine of an NGV. The marginal differences in term of permanent gas and hydrocarbons does not seems to originate from the compressor but rather on the fluctuating composition of natural gas coming from the network.

\subsection{Products Developed on the Basis of Hydraulic Piston Technology}

Hygen has implemented the hydraulic piston technology in three products: GasDroid, HYGEN+ and GasLiner.

\subsubsection{GasDroid}

GasDroid, (Fig. 6) is developed to TRL 8, i.e., the device is complete and qualified. 


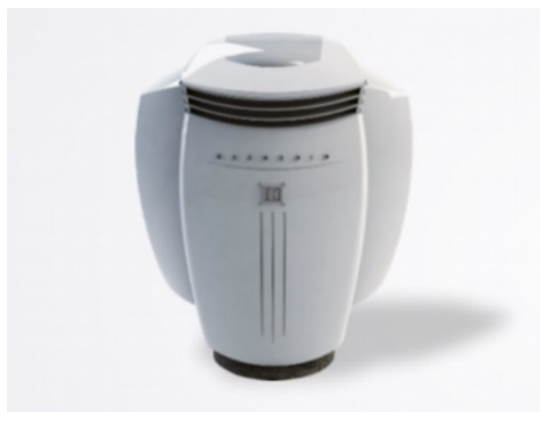

Fig. 6. VFA GasDroid.

GasDroid is a certified vehicle fuelling appliance (VFA) intended to fuel light duty vehicles with CNG and/or bio-CNG by self-flow of gas from GasDroid internal storage to the vehicle's fuel tank. GasDroid is equipped with two compression cylinders $33 \mathrm{~L}$ each and four storage cylinders $21 \mathrm{~L}$ each. GasDroid is capable to supply a vehicle with a portion of fuel providing $120-150 \mathrm{~km}$ of the daily run. The specifications of GasDroid are detailed in Table 3.

TABLE 3. SPECIFICATIONS OF GASDROID

\begin{tabular}{ll}
\hline Compression flow rate & $1.2 \mathrm{~m}^{3} / \mathrm{h}$ \\
Gas outlet pressure & $200 \mathrm{bars}$ \\
Storage capacity & $84 \mathrm{water}$ litres \\
Fuelling time & $4 \mathrm{~min}$ \\
Electrical power & $0.5 \mathrm{~kW} \max 6 \mathrm{~A}$ \\
Power supply line & $220 \mathrm{~V}$ \\
Gas inlet pressure & $17-25 \mathrm{mbar}$ or $3 \mathrm{bars}$ \\
Dimensions L x W x H (cm) & $90 \times 50 \times 1765 \mathrm{~cm}$ \\
Weight (with working liquid) & $390 \mathrm{~kg}$ \\
\hline
\end{tabular}

GasDroid can be installed on the biogas/biomethane production site to be operated as follows.

1. Preparation for the fuelling or high pressure gaining: biomethane is compressed within compressing cylinders and accumulated in the storage cylinders. Compression mode can last up to 3 hours, depending on the pressure of the biomethane on the outlet of the upgrade plant (usually 10 bar) and on the pressure left in the GasDroid internal storage after the previous fuelling.

2. Vehicle fuelling: compressed biomethane flows freely from the internal storage cylinders of GasDroid to the vehicle's fuel tank. Fuelling process lasts 4 minutes to equalize pressure between the storage and the target tank (approximately 80-110 bars, depending on the size of the target tank), thus supplying the vehicle with a daily portion of fuel for $100-150 \mathrm{~km}$ of run.

\subsection{2. $H Y G E N+$}

HYGEN+, (Fig. 7) is an Alpha prototype of VFA, which is supplied with the boosting feature. 


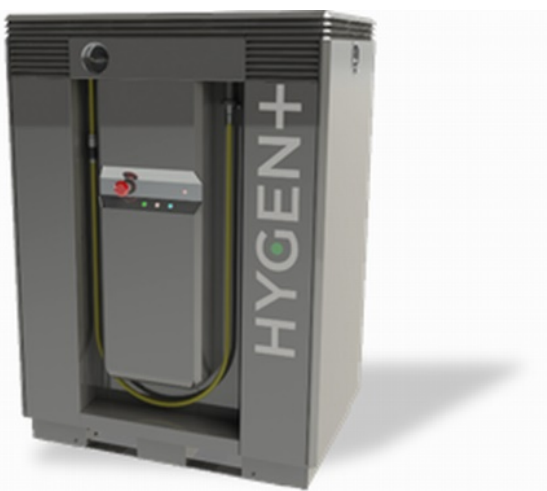

Fig. 7. VFA $H Y G E N+$ for commercial vehicle fuelling, with a boosting feature, manufactured by Hygen.

It has integrated four compression cylinders $33 \mathrm{~L}$ each and four storage cylinders $95 \mathrm{~L}$ each. The whole system is optimized for complete fuelling of vehicles having fuel tank capacity up to $300 \mathrm{~L}$, up to 200 bars in 15-20 minutes, depending on the remaining pressure in the vehicle's fuel tank before fuelling. The specifications of $H Y G E N+$ are detailed in Table 4.

TABLE 4. SPECIFICATIONS OF HYGEN+

\begin{tabular}{ll}
\hline Compression flow rate & $4.4 \mathrm{~m}^{3} / \mathrm{h}$ \\
Gas outlet pressure & $200 \mathrm{bars}$ \\
Storage capacity & 380 water litres \\
Fuelling time & up to $25 \mathrm{~min}$ for $60 \mathrm{~m}^{3}$ at 200 bars \\
Electrical power (2 pumps) & $4 \mathrm{~kW}$ max $7.9 \mathrm{~A}$ \\
Power supply line & $380 \mathrm{~V}($ three phase) \\
Gas inlet pressure & $17-25 \mathrm{mbar}$ or $3 \mathrm{bars}$ and above \\
Dimensions $\mathbf{L} \times \mathbf{W} \times \mathbf{H}(\mathbf{c m})$ & $120 \times 100 \times 170 \mathrm{~cm}$ \\
Weight (empty) & $1500 \mathrm{~kg}$ \\
\hline
\end{tabular}

$H Y G E N+$ can be installed at biomethane production site and serve for vehicle working as follows.

Preparation for the fuelling or high-pressure gaining that lasts for 4-6 hours, depending on the pressure of biomethane after purification (approximately 10 bars) and initial pressure in the storage after the previous fuelling. Biomethane will be compressed within compression cylinders and accumulated in the storage cylinders.

Vehicle fuelling proceeds in two stages:

Stage 1: Free flow of gas from the internal storage cylinders of HYGEN+ to the vehicle's fuel tank, that lasts for ca. 4 minutes to equilibrate pressure between the storage and the target tank (70-120 bars, depending on the size of the target tank);

Stage 2: Boosting - remained medium high pressure gas from the storage ( $70-120$ bars) is supplied to the inlet of the compression cylinders alternately for additional compression and pushed to the target tank, until 200 bars pressure in the target tank is achieved (it can take up to 6 compressing cycles to fill the target tank of $240 \mathrm{~L}$ ). 


\subsubsection{GasLiner}

For various off-grid situations Hygen proposes a cost-effective and convenient solution - a mobile bio-CNG system named GasLiner. Currently an Alpha prototype of GasLiner is developed. It is capable to:

- compress the gas (biomethane) by itself, i.e., without usage of a mother station;

- accumulate compressed to 250 bars gas in its storage cylinders;

- deliver gas (biomethane) to the selling/distribution points;

- fuel simultaneously any number of vehicles (being connected in parallel) with CNG (bio CNG) in 1.5 hours without using a daughter station.

Avoiding employing the mother and daughter stations in the virtual pipeline system, GasLiner allows a significant reduction of the whole virtual pipeline costs for all kind of gaseous fuels. GasLiner has a modular structure that allows to form a system of any capacity. Developed GasLiner module with dimensions $(\mathrm{L} \times \mathrm{W} \times \mathrm{H}) 162 \times 240 \times 271 \mathrm{~cm}$ is shown in Fig. 8. Eight modules can be placed on a standard platform, carrying up to $8000 \mathrm{~m}^{3}$ of $\mathrm{CNG} /$ bio-CNG) on board.

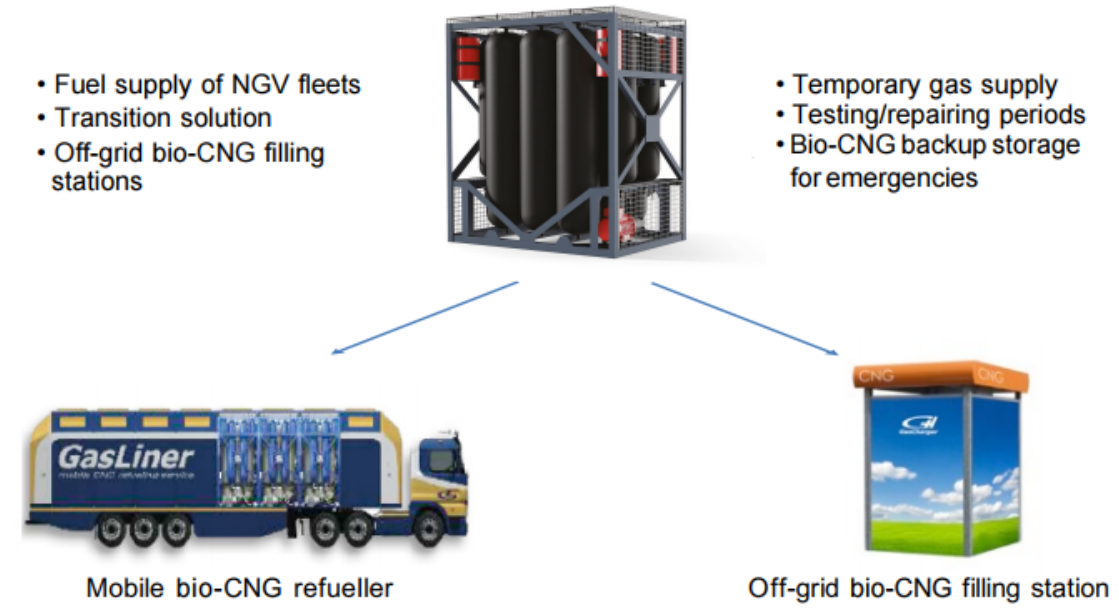

Fig. 8. GasLiner modules in mobile and stationary application.

As measured, off-grid fuelling process reached very high $98 \%$ efficiency with a flow rate of biomethane of $80 \mathrm{Nm}^{3} / \mathrm{min}$. Besides that, GasLiner module can also be used as the stationary fuelling off-grid station, to be supplied with bio-CNG by GasLiner mobile trailer and providing vehicles fast fuelling with $\mathrm{CNG} / \mathrm{bio}-\mathrm{CNG}$.

\section{Conclusion}

To accelerate the decarbonisation of the planet, the biomethane, as a motor fuel, has a promising potential. The greatest challenge for that is to create an efficient fuelling infrastructure. Hygen has developed an innovative technology of hydraulic piston, allowing to produce a wide spectrum of vehicle fuelling appliances for bio-CNG fuel. The further development of this technology shall be focused on creation of flexible solutions, applicable at biogas/biomethane, production sites, for bio-CNG compression, transportation and fast 
discharging to the NGVs or injection into the gas grid in a cost effective and convenient way. The technology has a great potential and needs to be explored and developed further for application with hydrogen. As stated by European Commission in 2020, hydrogen is predicted to be the fuel of the future [18], [19]. Hydraulic compression allows to achieve higher compression ratios required for hydrogen, solving the existing problems arising from employment of reciprocating compressors [20], as well as benefits the idea of combustion hydrogen enriched CNG in sparkle ignition engines of NGVs [21]. Potentially the technology of hydraulic piston allows to develop the emerging hydrogen market in two ways: enabling gas grid decarbonisation through hydrogen blending with natural gas and as a new compression solution for hydrogen as vehicle fuel.

\section{ACKNOWLEDGEMENT}

The research leading to these results has been supported by the European Regional Development Fund project "Competence Centre of Mechanical Engineering", contract No.1.2.1.1/18/A/008 signed between Competence Centre of Mechanical Engineering and Central Finance and Contracting Agency, Research No. 3.1. "Additional research and integration of the technology of hydraulic piston, aiming to develop and demonstrate economically efficient compressed natural gas smart commercial vehicle fuelling appliance". Our special gratitude to Gaspard Bouteau, $\mathrm{PhD}$, Research Engineer, who conducted the research work in Engie Lab CRIGEN. Co-authorship of Laboratory of Materials for Energy Harvesting and Storage, ISSP UL has been supported by the Ministry of Economics of the Republic of Latvia, project LAGAS No VPP-EM-INFRA-2018/10003. We are thankful to Alina Safronova, the master student of Riga Technical University, faculty of Power and Electrical Engineering for help in finding data and formatting this work.

\section{REFERENCES}

[1] Moraga J. L., Mulder M., Perey P. Future markets for renewable gases and hydrogen: what would be the optimal regulatory provisions? Brussels: Centre on Regulation in Europe, 2019.

[2] International Energy Agency. Global EC Outlook 2019, Paris: IEA, 2019

[3] JongRoul W., Hyunhong Ch., Joongha A. Well-to-wheel analysis of greenhouse gas emissions for electric vehicles based on electricity generation mix: A global perspective. Transportation Research Part D: Transport and Environment 2017:51:340-350. https://doi.org/10.1016/j.trd.2017.01.005

[4] NGVA Europe. Gas in Transport Manifesto. Policy recommendations [Online]. [Accessed 05.01.2020]. Available: https://www.ngva.eu/wp-content/uploads/2019/07/NGVA-Europe_gas-in-transport-manifesto_July2019.pdf

[5] $\mathrm{CO}_{2}$ emissions and carbon neutrality [Online]. [Accessed 05.01.2020]. Available: https://www.ngva.eu/index.php?s=well-to-wheel+GHG+emissions+in+CO2

[6] European Parliament and the Council. Directive 2014/94/EU of the European Parliament and of the Council of 22 October 2014 on the deployment of alternative fuels infrastructure. Official Journal of European Union 2014: L 307/1

[7] Natural and renewable gas: Joint call to accelerate the deployment of refuelling infrastructure_[Online]. [Accessed 15.02.2020]. Available: https://www.ngva.eu/medias/joint-call-for-the-acceleration-of-the-deployment-of-natural-andrenewable-gas-and-its-refuelling-infrastructure-across-the-eu-pr/

[8] European Parliament and the Council. Directive (EU) 2018/2001 of the European Parliament and of the Council of 11 December 2018 on the promotion of the use of energy from renewable sources. Official Journal of European Union 2018: L 328/82.

[9] Fachagentur Nachwachsende Rohstoffe e.V. Bioenergy in Germany. Facts and Figures 2017. Gülzow-Prüzen: Agency for Renewable Resources, 2017.

[10] Jopperta C. L., Perecina D., Santosa M. M., Coelhoa S. T., Camacho J. L. P. 2018. A short-cut model for predicting biomethane availability after biogas. Journal of Cleaner Production 2018:200:148-160. https://doi.org/10.1016/j.jclepro.2018.07.269

[11] CNG [Online]. [Accessed 15.02.2020]. Available: https://www.coltri.com/en/products/cng/

[12] FuelMaker CNG Refueling Stations [Online]. [Accessed 15.02.2020]. Available: http://gofuelmaker.com/

[13] Krakowski R. Analysis of Selected Simulated Failure of a Reciprocating Compressor Using Computer Diagnostic System. Journal of Kones 2019:25(2). https://doi.org/10.5604/01.3001.0012.2800

[14] Palczynski T., Kantyka K. Experimental and Numerical Investigations of Pipeline with Resonator. Mechanics and Mechanical Engineering 2019:23(1):17-22. https://doi.org/10.2478/mme-2019-0003 
$2020 / 24$

[15] Deymi-Dashtebayaz M., Farzaneh Gord M., Reza Rahbari H. Studying Transmission of Fuel Storage Bank to NGV Cylinder in CNG Fast Filling Station. Journal of the Brazilian Society of Mechanical Sciences and Engineering 2012:34(4):429-435. https://doi.org/10.1590/S1678-58782012000400002

[16] World Intellectual Property Organisation [Online]. [Accessed 16.02.2020]. Available: https://patentscope.wipo.int/search/en/detail.jsf?docId=WO2009035311

[17] Comite Europeen de Normalisation. EN 16723-2:2017 Natural gas and biomethane for use in transport and biomethane for injection in the natural gas network - part 2: Automotive fuels specification. Available: https://infostore.saiglobal.com/en-us/Standards/EN-16723-2-2017-342578_SAIG_CEN_CEN_784469

[18] Communication from the Commission to the European Parliament, the Council, the European Economic and Social Committee and the Committee of the Regions. Powering a climate-neutral economy: An EU Strategy for Energy System Integration. Available: https://op.europa.eu/en/publication-detail/-/publication/5ba29377-c135-11ea-b3a401aa75ed71a1/

[19] Communication from the Commission to the European Parliament, the Council, the European Economic and Social Committee and the Committee of the Regions. A hydrogen strategy for climate-neutral Europe. Available: https://op.europa.eu/en/publication-detail/-/publication/5602f358-c136-11ea-b3a4-01aa75ed71a1/

[20] Białek P., Bielawski P. Failure analysis of refinery hydrogen reciprocating compressors. Diagnostyka 2018:19(1):8392. http://dx.doi.org/10.29354/diag/82961

[21] Juknelevičius R., Mehra R. K., Ma F., Szwaja S. In-Cylinder Combustion Analysis of a SI Engine Fuelled with Hydrogen Enriched Compressed Natural Gas (HCNG): Engine Performance, Efficiency and Emissions. Journal of Kones 2018:25(3). https://doi.org/10.5604/01.3001.0012.4340 